\title{
Transplantation of MHC-mismatched mouse embryonic stem cell-derived thymic epithelial progenitors and MHC-matched bone marrow prevents autoimmune diabetes
}

\author{
Min Su ${ }^{1,2}$, Yujun Lin' ${ }^{2}$ Zhixu He ${ }^{3,4^{*}}$ and Laijun Lai ${ }^{2,5^{*}}$ (1)
}

\begin{abstract}
Background: Type 1 diabetes (T1D) is an autoimmune disease resulting from the destruction of insulin-secreting islet $\beta$ cells by autoreactive T cells. Non-obese diabetic (NOD) mice are the widely used animal model for human T1D. Autoimmunity in NOD mice is associated with particular major histocompatibility complex (MHC) loci and impaired islet autoantigen expression and/or presentation in the thymus, which results in defects in both central and peripheral tolerance. It has been reported that induction of mixed chimerism with MHC-mismatched, but not MHC-matched donor bone marrow (BM) transplants prevents the development T1D in NOD mice. We have reported that mouse embryonic stem cells (mESCs) can be selectively induced in vitro to generate thymic epithelial progenitors (TEPs) that further develop into thymic epithelial cells (TECs) in vivo to support T cell development.
\end{abstract}

Methods: To determine whether transplantation of MHC-mismatched mESC-TEPs could prevent the development of insulitis and T1D, NOD mice were conditioned and injected with MHC-mismatched B6 mESC-TEPs and MHC-matched $\mathrm{BM}$ from $\mathrm{H}-2^{\mathrm{g} 7} \mathrm{~B} 6$ mice. The mice were monitored for T1D development. The pancreas, spleen, BM, and thymus were then harvested from the mice for evaluation of T1D, insulitis, chimerism levels, and T cells.

Results: Transplantation of MHC-mismatched mESC-TEPs and MHC-matched donor BM prevented insulitis and T1D development in NOD mice. This was associated with higher expression of proinsulin 2, a key islet autoantigen in the mESC-TECs, and an increased number of regulatory T cells.

Conclusions: Our results suggest that embryonic stem cell-derived TEPs may offer a new approach to control T1D.

Keywords: Type 1 diabetes, Embryonic stem cells, Thymic epithelial cells, Autoreactive T cells, Regulatory T cells

\section{Background}

Type 1 diabetes (T1D) is an autoimmune disease caused by the destruction of insulin-secreting islet $\beta$ cells by autoreactive $T$ cells $[1-4]$. Non-obese diabetic (NOD) mice, the most commonly used animal model for human T1D, share many of the disease characteristics including genetic risk factors, autoantigens, and the chronicity of

\footnotetext{
*Correspondence: hzx@gmc.edu.cn; laijun.lai@uconn.edu

${ }^{3}$ Key Laboratory for Adult Stem Cell Translational Research, Chinese Academy of Medical Sciences, Guiyang 550004, China

${ }^{2}$ Department of Allied Health Sciences, University of Connecticut, 1390 Storrs Road, Storrs, CT 06269, USA

Full list of author information is available at the end of the article
}

autoimmunity [5]. Although many T1D genetic risk factors have been identified [6], the major histocompatibility complex (MHC) or human leukocyte antigen (HLA) is the major factor $[1,3]$. The disease susceptibility in NOD mice or T1D patients is linked to particular MHC or HLA such as I-Ag7 or HLA-DR4 and HLA-DQ8 $[7,8]$. The I-Ag7 has been shown to be unstable, and a poor peptide binder $[9,10]$. This "functional instability" could lead to a defect in thymic deletion of autoreactive $\mathrm{T}$ cells [9-12]. Insufficient presentation of self-antigen in the thymus can also affect the development of the antigenspecific regulatory T cells (Tregs) [3]. 
Transgenic expression of diabetes-protective MHC alleles in the thymus has been reported to prevent T1D development in NOD mice [13, 14]. However, this approach cannot readily be translated to humans. Induction of either mixed or complete chimerism with MHCmismatched nonautoimmune donor BM transplants also prevented the development of T1D in NOD mice [15-21]. In contrast, induction of mixed chimerism with MHCmatched nonautoimmune donor BM transplants did not prevent the development of T1D in NOD mice [19, 21]. However, in clinical settings, allogeneic BM transplantation (BMT) has the risk of inducing graft-versus-host disease (GVHD) [22].

Another strong T1D genetic risk factor is associated with a variable number of tandem repeat minisatellites, upstream of the insulin gene that modulates thymic (but not pancreatic) expression of this antigen [1]. Insulin/ proinsulin is a key autoantigen in initiating anti-islet autoimmunity [23-25]. In humans, the variant that has a shorter stretch of repeats has a lower expression of insulin in the thymus, and predisposes to T1D [26, 27]. NOD mice with a deletion of the insulin 2 gene have an accelerated T1D development [28]. In contrast, transgenic expression of insulin in the thymus induces immune tolerance to the autoantigen and prevents T1D development [23]. Intrathymic injection of insulin also has the potential to prevent T1D development $[29,30]$. However, to achieve this tolerance, the thymus, the major organ implicated in self-tolerance induction, has to be sufficiently functional. It is well known that the thymus undergoes age-dependent involution, and its functions are seriously compromised in the elderly [31].

$\mathrm{T}$ cell development occurs in the thymus, and is critically dependent on the thymic microenvironment, in which thymic epithelial cells (TECs) are the major component. However, TECs undergo both qualitative and quantitative loss over time, which is the major factor for age-dependent thymic involution. We have reported that mouse embryonic stem cells (ESCs) (mESCs) can be selectively induced to generate thymic epithelial progenitors (TEPs) in vitro [32]. When transplanted into mice, the mESC-TEPs further develop into TECs, reconstitute normal thymic architecture, and support T cell development [32, 33]. We have also shown that transplantation of mESC-TEPs expressing self-antigen myelin oligodendrocyte glycoprotein (MOG) in mice results in immune tolerance to the MOG and the prevention of experimental autoimmune encephalomyelitis (EAE) development $[34,35]$. Furthermore, transplantation of donor-origin mESC-TEPs into GVHD recipients induces immune tolerance to both donor and host antigens and prevents the development of chronic GVHD [36].

In this study, we determined the ability of MESC-TEPs to prevent T1D. We show here that transplantation of
MHC-mismatched C57BL/6 (B6) mESC-TEPs and MHC-matched nonautoimmune donor BM prevents insulitis and T1D development in NOD mice that were pre-conditioned with anti-CD3/CD8 antibodies (Abs). This is associated with establishing diabetes-protective MHC alleles, increasing the expression of proinsulin 2 (Ins2) in the thymus, and improving the thymic microenvironment, thereby the restoration of defective negative selection to insulin in NOD mice. In addition, transplantation of the mESC-TEPs leads to an increased number and function of Tregs in the thymus and the spleen.

\section{Methods \\ Mice}

Female NOD/LtJ, B6, and $\mathrm{H}-2^{\mathrm{g} 7}$ B6 mice were purchased from The Jackson Laboratory (Bar Harbor, ME). All experimental procedures involving mice were approved by the University of Connecticut Animal Care and Use Committee and were conducted in accordance with NIH guidelines.

\section{mESC culture and differentiation}

To induce the differentiation of mESCs into TEPs, B6 $\mathrm{mESC}$ and $\mathrm{GFP}^{+} \mathrm{B} 6 \mathrm{mESC}$ lines (from Cyagen, Santa Clara, CA) were first differentiated into definitive endoderm (DE), and then TEPs as described [36].

\section{Immunomagnetic cell separation}

Single-cell suspensions from differentiated mESCs were harvested after the cells were treated with $2 \mathrm{mg} / \mathrm{ml}$ collagenase IV. The cells were stained with PE-labeled anti-mouse EpCAM1 antibody, washed, and stained with anti-PE MicroBeads (Miltenyi Biotec, Auburn, CA). EpCAM1 ${ }^{+}$and $\mathrm{EpCAM}^{-}$cells were selected using a magnetic-activated cell sorter immunomagnetic separation system (Miltenyi Biotec). Similarly, depletion of $\mathrm{CD}_{4}^{+}$cells from splenocytes, and isolation of $\mathrm{CD}^{4} 5^{-} \mathrm{EpCAM}^{+}$TECs were performed with immunomagnetic separation.

\section{Induction of mixed chimerism in NOD mice}

Six-week-old NOD mice were conditioned with sequential injection of FcR- nonbinding anti-CD3c $F\left(a b^{\prime}\right)$ fragment and FcR binding (FB) anti-CD3 (clone 145-2C11, from BioXCell) in addition to anti-CD8 (clone 116-13.1, from BioXCell) Abs as described [19, 21]. On day 0, the mice were injected i.v. with $\mathrm{BM}$ and $\mathrm{CD} 4^{+} \mathrm{T}$-depleted spleen cells from MHC-mismatched B6 $(\mathrm{H}-2 \mathrm{~b})$ or MHC-matched congenic H-2 g7 B6 mice $\left(20 \times 10^{6}\right.$ each). Some of the mice were injected intrathymically (i.t.) with mESC-TEPs $\left(\right.$ EpCAM $^{+}$cells, $5 \times 10^{4}$ ) or $\mathrm{mESC}$-control cells $\left(E p C A M 1^{-}\right.$cells, $\left.5 \times 10^{4}\right)$ on day 0 with a procedure as described [37]. 


\section{Flow cytometry analysis}

Single-cell suspensions of the thymus, spleen, graft, and $\mathrm{mESC}$-derived cells were stained with the fluorochromeconjugated Abs as described [32, 33, 37, 38]. For intracellular staining, the cells were first permeabilized with a BD Cytofix/Cytoperm solution for $20 \mathrm{~min}$ at $4{ }^{\circ} \mathrm{C}$. Direct or indirect staining of fluorochrome-conjugated Abs included: CD4, CD8, CD3, CD25, Foxp3, CD45, Ly51, and EpCAM1 (BioLegend or BD Biosciences, San Diego, CA), keratin (k)5 (SantaCruz Biotechnology, Santa Cruz, CA), k8 (US Biological, Swampscott, MA), fluorescein isothiocyanate, or phycoerythrin labeled anti-rat, or rabbit IgG (BD Biosciences). The samples were analyzed with an LSRFortessa X-20 Cell Analyzer (BD Biosciences). Data analysis was done using FlowJo software (Ashland, OR).

\section{Determination of suppressive activity of Tregs}

Effector $\mathrm{T}$ cells (Teffs) $\left(\mathrm{CD} 4^{+} \mathrm{CD} 25^{-}\right)$and Tregs $\left(\mathrm{CD} 4^{+} \mathrm{CD} 25^{+}\right)$were purified from NOD mice by an immunomagnetic system (Miltenyi, Auburn, CA), and the purity of the cells was usually $>90 \%$. The Teffs were stimulated with anti-CD3 antibody (Biolegend) in the presence of Tregs at a ratio of 2: 1 . The proliferation of T cells was assessed by pulsing the culture with $\left[{ }^{3} \mathrm{H}\right]$ thymidine $(1 \mu \mathrm{Ci} /$ well) (PerkinElmer, Inc., Downers Grove, IL) $12 \mathrm{~h}$ before harvest. Incorporation of $\left[{ }^{3} \mathrm{H}\right]$ thymidine was measured by liquid scintillation spectroscopy (PerkinElmer, Inc.). The suppression index $=$ [proliferation (evaluated by CPM) without Tregs - CPM with Tregs]/CPM without Tregs.

\section{Real-time quantitative reverse-transcription and polymerase chain reactions (qRT-PCR)}

Total RNA was isolated from cells, and cDNA was synthesized as described [36]. qRT-PCR was performed with the Power SYBR green mastermix (Applied Biosystems, UK) using the 7500 real-time PCR system (Applied Biosystems, UK).

\section{Statistical analysis}

$P$ values were based on the two-sided Student's $t$ test. A confidence level above $95 \%(p<0.05)$ was determined to be significant.

\section{Results}

Induction of mixed chimerism with MHC-mismatched but not matched BM transplants prevents insulitis and T1D development in NOD mice

It has been reported that BM cells in combination with donor $\mathrm{CD}^{+} \mathrm{T}$ cells induced stable permanent mixed chimerism without GVHD [17]. Dr. Zeng's group has also reported that induction of mixed chimerism with MHC-mismatched but not matched BM transplants prevents insulitis and T1D development in NOD mice pre-conditioned with anti-CD3/CD8 Abs [19]. We have used similar protocols reported by this group. Six-weekold NOD mice $\left(\mathrm{H}-2 \mathrm{k}^{\mathrm{d}}, \mathrm{I}-\mathrm{A}^{\mathrm{g} 7}, \mathrm{CD} 45.1\right)$ were conditioned with anti-CD3 and anti-CD8 Abs on days -8 and -3 . On day 0 , the mice were injected i.v. with $\mathrm{BM}$ and $\mathrm{CD} 4^{+}$ $\mathrm{T}$ cell-depleted spleen cells $\left(20 \times 10^{6}\right.$ each $)$ from MHCmismatched B6 (H-2k $\left.{ }^{\mathrm{b}}, \mathrm{I}-\mathrm{A}^{\mathrm{b}}, \mathrm{CD} 45.2\right)$ or MHC-matched congenic $\mathrm{H}-2^{\mathrm{g} 7}$ B6 $\left(\mathrm{H}-2 \mathrm{k}^{\mathrm{d}}, \mathrm{I}-\mathrm{A}^{\mathrm{g} 7}, \mathrm{CD} 45.2\right)$ mice. The control mice were given a conditioning regimen only.

The mice were then monitored for T1D development by analyzing blood glucose levels. On day 100 , the mice were euthanized and the blood, pancreas, spleen, BM, and thymus of the mice were harvested for evaluation of T1D, insulitis, and chimerism levels. As shown in Fig. 1a, 100 days after BMT, $68 \%$ and $57 \%$ of the CD3/CD8 conditioned control mice and the MHC-matched BMT mice developed T1D, respectively. In contrast, none of the MHC-mismatched BMT mice developed T1D. Furthermore, $89 \%$ and $72 \%$ of the residual islets in the control mice and the MHC-matched BMT mice had insulitis, respectively (Fig. 1b). However, none of the islets in the MHC-mismatched BMT mice had insulitis, although a small portion of them showed peri-insulitis (Fig. 1b).

We then evaluated chimerism levels in the recipients at the end of experiments (on day 100 after BMT). There were no significant differences in the chimerism levels between the MHC-matched and MHC-mismatched BMT mice. In both groups, the spleens contained 30-40\% host-type $\mathrm{TCR}^{+} \mathrm{T}$ cells and $\mathrm{B}^{2} 20^{+} \mathrm{B}$ cells (Fig. 1c, isotype controls in this figure and other figures are shown in Additional file 1: Figure S1), and the BM contained 45-49\% host-type B220 ${ }^{+}$B cells (Fig. 1d). De novo developed $\mathrm{CD}^{+} \mathrm{CD}^{+}$DP thymocytes also existed in both MHC-matched and MHC-mismatched BMT mice (Fig. 1e). However, the percentage of host-type DP thymocytes in the MHC-mismatched BMT mice was three to fourfold lower than that in MHC-matched mice (Fig. 1e), indicating negative selection occurred in the MHC-mismatched BMT mice.

Taken together, our results confirmed the previous reports that mixed chimerism was present in the NOD mice conditioned with anti-CD3/CD8 Abs and followed by either MHC-matched or MHC-mismatched BMT. Induction of mixed chimerism with MHC-mismatched but not matched BM transplants prevents insulitis and T1D development in these mice.

Transplantation of MHC-mismatched mESC-TEPs prevents insulitis and T1D development in the MHC-matched BMT NOD mice

We then determined whether transplantation of $\mathrm{MHC}$ mismatched mESC-TEPs could prevent the development of insulitis and T1D in NOD mice. To this end, NOD 


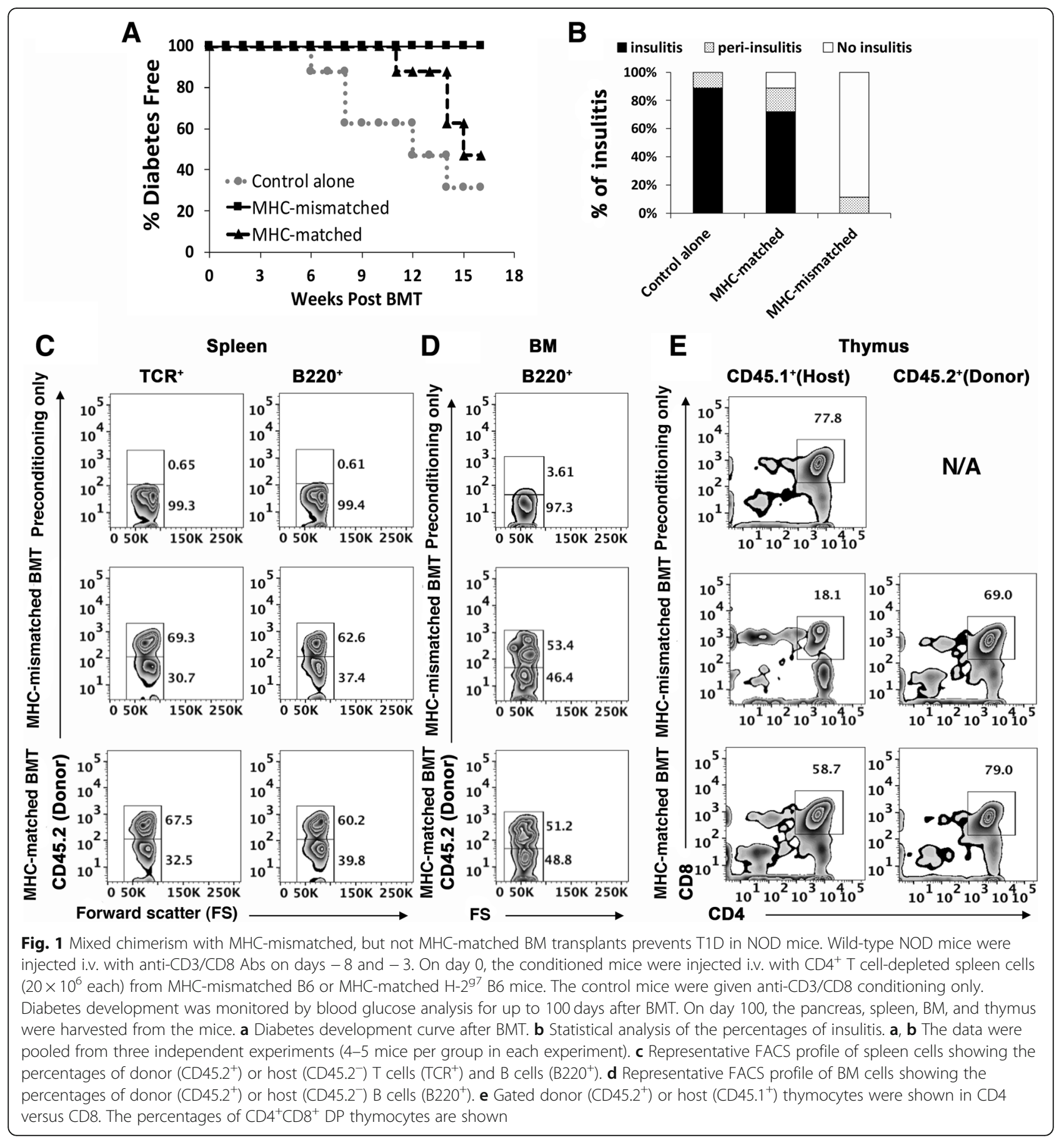

mice were conditioned with anti-CD3 and anti-CD8 Abs and injected i.v. with $\mathrm{BM}$ and $\mathrm{CD}^{+}{ }^{+} \mathrm{T}$ cell-depleted spleen cells $\left(20 \times 10^{6}\right.$ each $)$ from MHC-matched $\mathrm{H}-2^{\mathrm{g} 7}$ B6 mice as described above. Groups of the BMT recipient were also injected i.t. with MHC-mismatched B6 mESC-TEPs (EpCAM1 ${ }^{+}$cells) or mESC-control cells (EpCAM1- cells).

The mice were monitored for T1D development. On day 100 , the pancreas, spleen, BM, and thymus were harvested from the mice for evaluation of T1D, insulitis, and chimerism levels. As shown in Fig. 2a, 100 days after BMT, 53\% of the MHC-matched BMT control mice developed T1D. Transplantation of mESC-derived control cells (EpCAM1 ${ }^{-}$cells) did not reduce the incidence of T1D. In contrast, transplantation of mESC-TEPs prevented the development of T1D with none of the mice having T1D. Furthermore, $78 \%$ and $73 \%$ of the residual islets in the MHC-matched BMT control mice or mESC- 


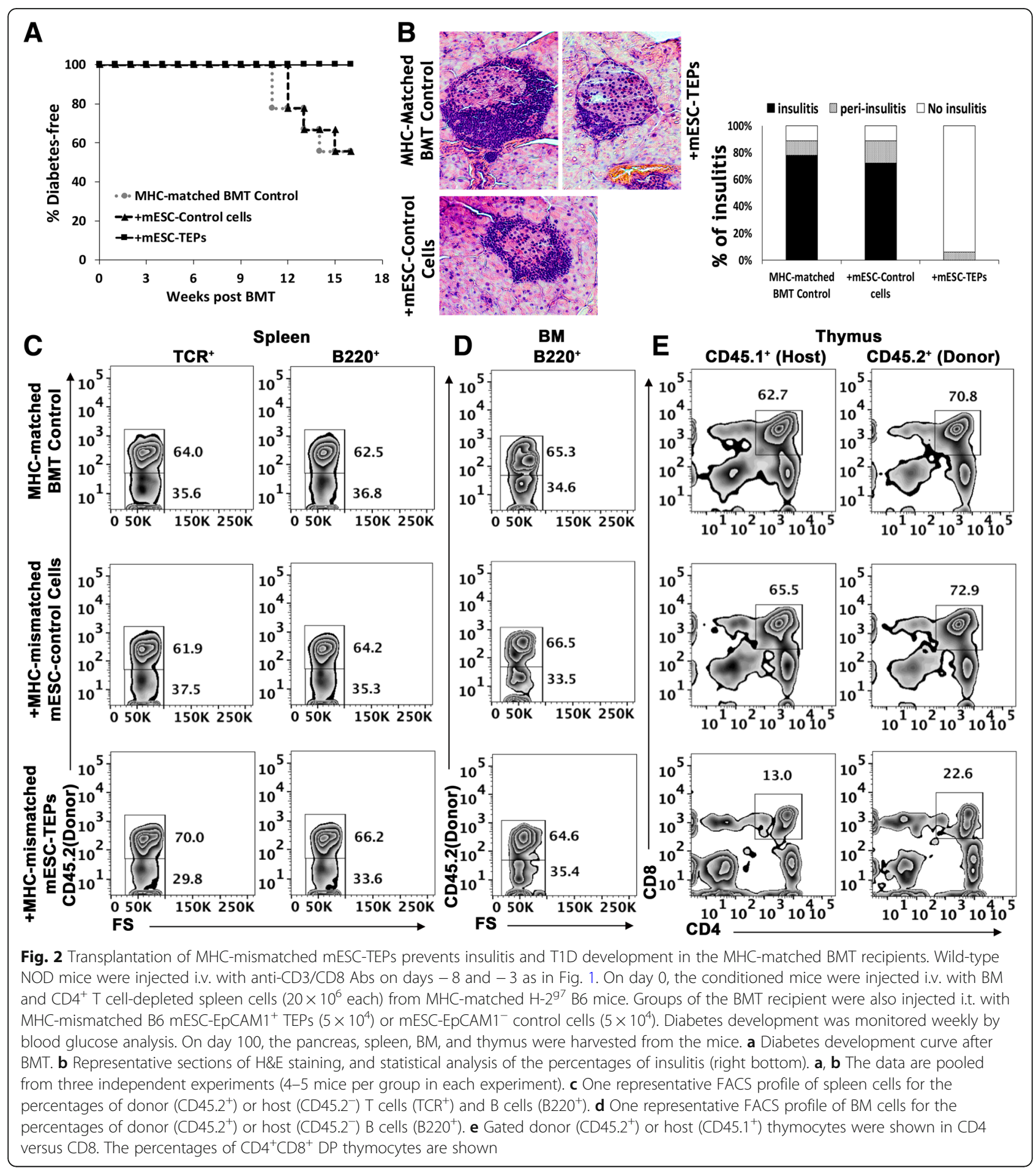

control cell-transplanted mice had insulitis, respectively (Fig. 2b). In contrast, none of the islets in the MESC-TEPtransplanted mice had insulitis, although a small portion of them showed minor peri-insulitis (Fig. 2b).

We then evaluated chimerism levels in the BMT recipients. Again, there were no significant differences in the chimerism levels among the 3 groups, and the spleens in each group contained $29-40 \%$ host-type $\mathrm{TCR}^{+} \mathrm{T}$ cells

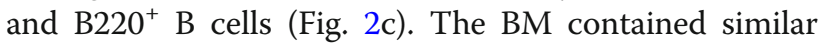
percentages of host-type B220 ${ }^{+}$B-cells (Fig. 2d). Host $\mathrm{CD}^{+}{ }^{+} \mathrm{CD}^{+}$DP thymocytes also de novo developed in all of the mice (Fig. 1e). Similar to the MHC-mismatched BMT recipients, the percentage of donor and host DP thymocytes in the mESC-TEP-transplanted mice was 
three to fivefold lower than that in MHC-matched BMT control mice or mESC-control cell-transplanted mice, suggesting negative selection occurred in the mESCTEP-transplanted mice.

Taken together, our results suggest that transplantation of MHC-mismatched mESC-TEPs results in the prevention of insulitis and T1D development in MHC-matched BMT mice, which is due, at least partly, to the deletion of autoreactive host $\mathrm{T}$ cells in the thymus.

\section{Transplantation of MHC-mismatched ESC-TEPs into the MHC-matched BMT recipients leads to an increased number and function of Tregs}

Accumulating data have shown that Tregs play an important role in controlling T1D [3, 39]. Since TECs can support Treg development, we analyzed Tregs in the NOD mice that had been subjected to MHC-matched BMT alone, or MHC-matched BMT plus MHC-mismatched EpCAM1 ${ }^{+}$ mESC-TEPs or mESC- EpCAM1 ${ }^{-}$control cells as shown in Fig. 2. As shown in Fig. 3a-d, the number of Tregs in the thymus and spleen of mESC-TEP-treated recipients were two to threefold higher than that in MHC-matched BMT control mice or mESC- EpCAM1 ${ }^{-}$control celltransplanted mice. It is likely that the increased number of Tregs is also responsible for the prevention of diabetes in mESC-TEP-transplanted NOD mice.

To determine whether the Tregs were functional, we evaluated the ability of the Tregs to inhibit the proliferation of Teffs from NOD mice. $\mathrm{CD} 4^{+} \mathrm{CD} 25^{+}$Tregs were purified from the spleen of MHC-matched BMT control

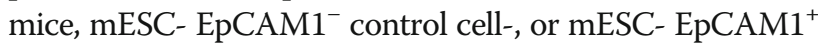
TEP-transplanted mice. $\mathrm{CD} 4^{+} \mathrm{CD} 25^{-}$Teffs were purified from wild-type NOD mice. The Teffs were stimulated with anti-CD3 antibody in vitro in the presence or absence of the Tregs. Cell proliferation was determined by $\left[{ }^{3} \mathrm{H}\right]$ thymidine incorporation 3 days later. As shown in Fig. 3e, Tregs from mESC-TEP-treated recipients had about twofold higher activity than those from control mice in inhibiting the proliferation of Teffs. The data indicate that the Tregs from mESC-TEP-treated recipients were functional.

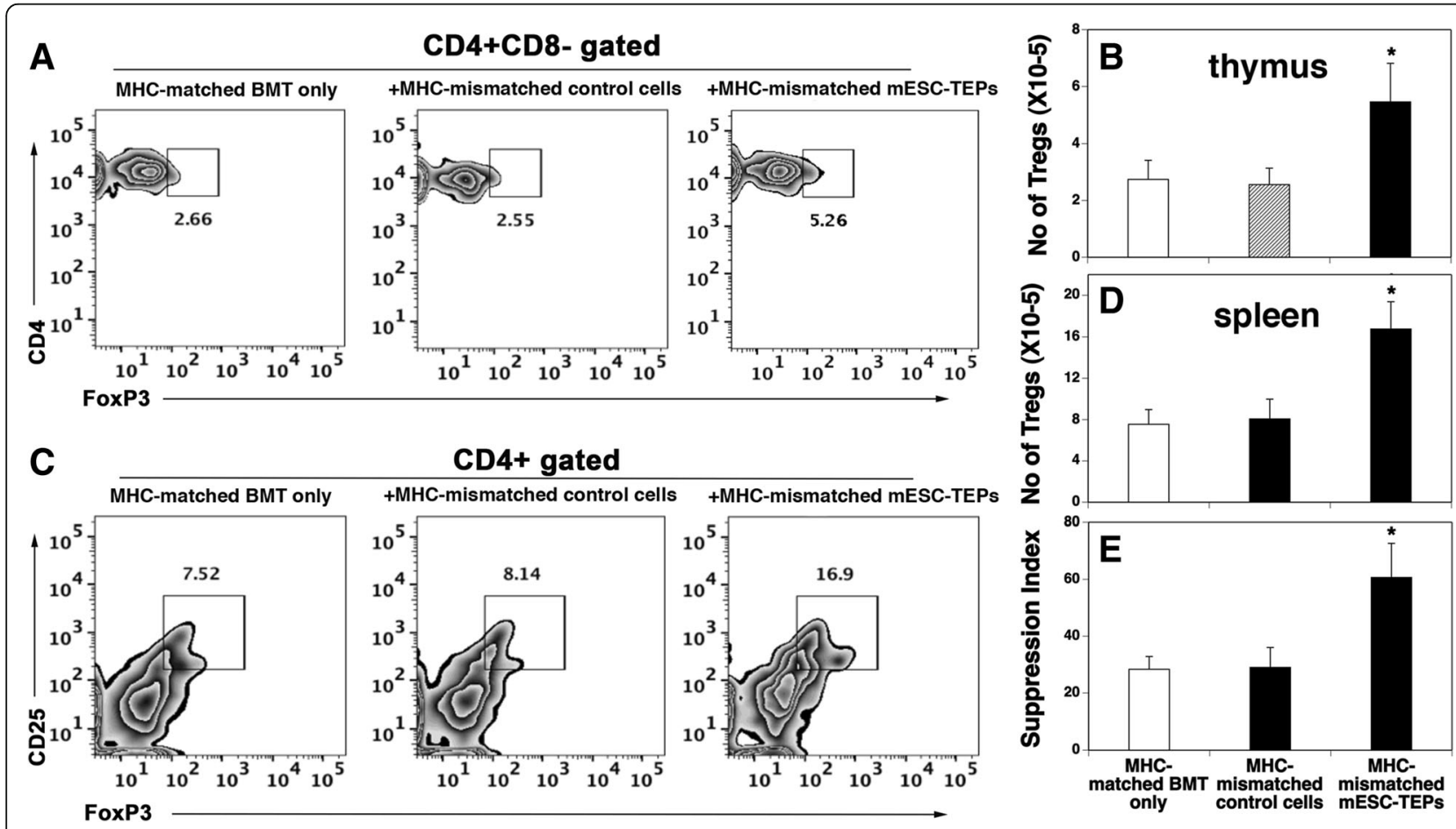

Fig. 3 mESC-TEP-treated recipients have an increased number and function of Tregs. NOD mice were injected i.v. with anti-CD3/CD8 Abs on days -8 and -3 . On day 0 , the conditioned mice were injected i.v. with BM and $\mathrm{CD}^{+}{ }^{+} \mathrm{T}$ cell-depleted spleen cells from $\mathrm{MHC}-$ matched $\mathrm{H}-2^{97} \mathrm{~B} 6$ mice. Groups of the BMT recipient were also injected i.t. with MHC-mismatched B6 mESC-EpCAM1 ${ }^{+}$TEPs or mESC-control cells (EpCAM1 ${ }^{-}$cells) as in Fig. 2. On day 100, Tregs in the thymus and spleen were analyzed by flow cytometry. a Representative flow cytometric profiles showing thymic Tregs. $\mathbf{b}$ The number of thymic $\mathrm{CD}^{+} \mathrm{CD}^{-} \mathrm{CD}^{+} \mathrm{FoxP}^{+}$Tregs from each group. $\mathbf{c}$ Representative flow cytometric profiles showing the Tregs in the spleen of the recipients. $\mathbf{d}$ The number of splenic $\mathrm{CD} 4^{+} \mathrm{CD} 25^{+} \mathrm{FoxP} 3^{+}$Tregs from each group. e $\mathrm{CD} 4^{+} \mathrm{CD} 25^{+}$Tregs were purified from the spleen of each group. $C D 4^{+} \mathrm{CD} 25^{-}$Teffs were purified from wild-type NOD mice. The Teffs were stimulated with anti-CD3 antibody $(0.5 \mu \mathrm{g} / \mathrm{ml}) \mathrm{in}$ the presence or absence of Tregs at a ratio 2:1 for 3 days. The proliferation of Teffs was measured by $\left.{ }^{3} \mathrm{H}\right]$ thymidine incorporation. The results are presented as suppression index. c-e The data are expressed as mean \pm SD from one of three independent experiments with similar results (4-5 mice per group in each experiment). ${ }^{*} P<0.05$, compared with mice given MHC-matched BMT only 
MHC-mismatched mESC-derived TECs express higher level of proinsulin than host TECs

Many studies have shown that insulin/proinsulin is the key autoantigen in initiating the autoimmunity of T1D [23-25]. Proinsulin is the pre-form of insulin. Mice have two proinsulin genes, Ins1 and Ins 2. Ins1 is exclusively expressed in the pancreas and Ins 2 is expressed in both thymus and pancreas [40]. We have previously reported that most of mESC-TEPs develop into cTECs $\left(\mathrm{CD} 45^{-} \mathrm{Ep}-\right.$ $\left.\mathrm{CAM}^{+} \mathrm{Ly}_{51}{ }^{+}\right)$and mTECs $\left(\mathrm{CD} 45^{-} \mathrm{EpCAM}^{+} \mathrm{Ly} 51^{-}\right)$in vivo [38]. We analyzed the expression levels of Ins 2 in total TECs $\left(\mathrm{CD}^{2} 5^{-} \mathrm{EpCAM}^{+}\right)$by qRT-PCR. By using $\mathrm{GFP}^{+} \mathrm{B} 6$ mESCs to separate mESC-TECs $\left(\mathrm{GFP}^{+} \mathrm{CD}^{-} 5^{-} \mathrm{EpCAM}^{+}\right)$ and host TECs $\left(\mathrm{GFP}^{-} \mathrm{CD} 45^{-} \mathrm{EpCAM}^{+}\right)$, we found that the expression level of Ins 2 in mESC-TECs was about twofold higher than that in host TECs (Fig. 4).

Transplantation of MHC-mismatched mESC-TEPs does not lead to an upregulation of PD-1 and downregulation of IL-7Ra on host-type peripheral T cells

It has been reported that, in MHC-mismatched BMtransplanted NOD mice, the residual host-type peripheral $\mathrm{T}$ cells were anergic caused by the upregulation of PD-1 and downregulation of IL-7R $\alpha$ [21]. We determined whether this also occurred in the mESC-TEPtransplanted NOD recipients. Consistent with a previous report, the expression of PD-1 was about twofold

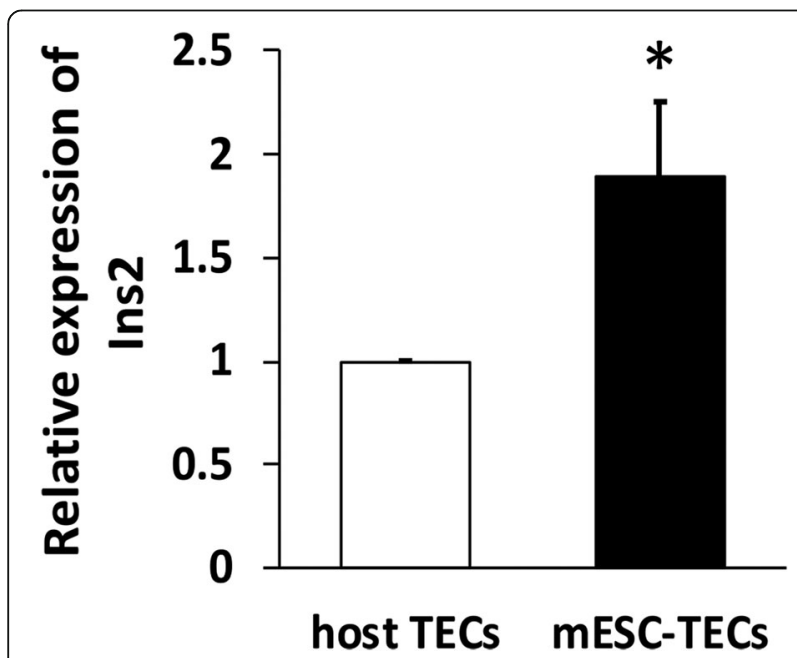

Fig. 4 mESC-TECs express higher levels of proinsulin than host TECs. Anti-CD3/CD8 conditioned NOD mice were injected i.v. with BM and $\mathrm{CD}^{+} \mathrm{T}$ cell-depleted spleen cells from MHC-matched $\mathrm{H}-2^{\mathrm{g}^{7}}$ B6 mice and i.t. with $\mathrm{GFP}^{+} \mathrm{B} 6 \mathrm{mESC}-\mathrm{EpCAM} 1^{+}$TEPs as in Fig. 2. On day 100, the thymi were harvested from the mice, and mESC-TECs (GFP ${ }^{+}$ $\mathrm{CD}^{-} 5^{-} \mathrm{EpCAM}^{+}$) or host TECs $\left(\mathrm{GFP}^{-} \mathrm{CD}^{-} 5^{-} \mathrm{EpCAM}^{+}\right)$were isolated. The expression of Ins2 in the mESC-TECs and host TECs was analyzed by qRT-PCR. Expression levels for each gene were normalized to the housekeeping gene GAPDH and are presented as relative expression compared with host TECs. Data show one of three independent experiments with similar results increased and the expression of and IL-7R $\alpha$ was about twofold decreased on the host-type T cells of MHC-mismatched BM-transplanted NOD mice, as compared with those in MHC-matched BM-transplanted mice (Fig. 5). However, the expression of PD-1 and IL-7R $\alpha$ was not increased or decreased on the host-type T cells of ESCTEP-transplanted mice. We also analyzed the expression of FAS and TIM3, molecules related to apoptosis and T cell exhaustion, and did not find a significant difference among the groups. Therefore, the peripheral tolerance mechanisms induced by MHC-mismatched BM transplants and mESC-TEPs appear to be different.

\section{Discussion}

In this study, we demonstrate that induction of mixed chimerism with MHC-matched BM transplants from nonautoimmune donors cannot prevent the development of insulitis and T1D in NOD mice, consistent with other reports $[19,21]$. In contrast, transplantation of MHC-mismatched mESC-TEPs prevents insulitis and T1D development in MHC-matched BMT NOD mice. Although induction of mixed chimerism with MHC-mismatched BM transplants also prevents the development of insulitis and T1D in NOD mice, the underlying mechanisms appear to be different from those from the transplantation of MHC-mismatched mESC-TEPs.

It has been reported that NOD or T1D patients have a defect in central tolerance [9-12, 41]. Transplantation of MHC-mismatched BM cells or MHC-mismatched mESCTEPs, at least partly, corrected the negative selection, resulting in the deletion of autoreactive T cells in the thymus. However, the former was mediated by donor DCs [19], whereas the latter was mediated by mESC-TECs.

The autoimmunity in NOD mice is related to the $\mathrm{I}-\mathrm{A}^{\mathrm{g} 7}$ $[7,8]$. It has been shown that the I- $\mathrm{A}^{\mathrm{g} 7}$ has a weak and unstable peptide-binding property, leading to the defect in thymic negative selection $[9,10]$. Conversely, transgenic NOD mice that express MHC class II genes other than I$\mathrm{A}^{\mathrm{g} 7}$ prevent T1D development $[13,14]$. The prevention of diabetes in the MHC-mismatched B6 mESC-TEP-transplanted NOD mice is probably, at least partly, due to introducing protective MHC molecules in TECs.

We have also shown that mESC-derived TECs expressed a higher level of Ins 2 than host TECs in the NOD mice. Although multiple inlet autoantigens have been implicated in T1D, insulin/proinsulin is a major autoantigen associated with T1D [23-25]. It has been shown that thymic insulin levels play a critical role in insulin-specific $\mathrm{T}$ cell self-tolerance. Lower levels of insulin expression in the thymus are associated with the generation of autoreactive $\mathrm{T}$ cells and the development of T1D [1, 40, 42]. Therefore, the higher expression of proinsulin in the mESC-TECs may also contribute to the restoration of defective negative selection in NOD mice. 

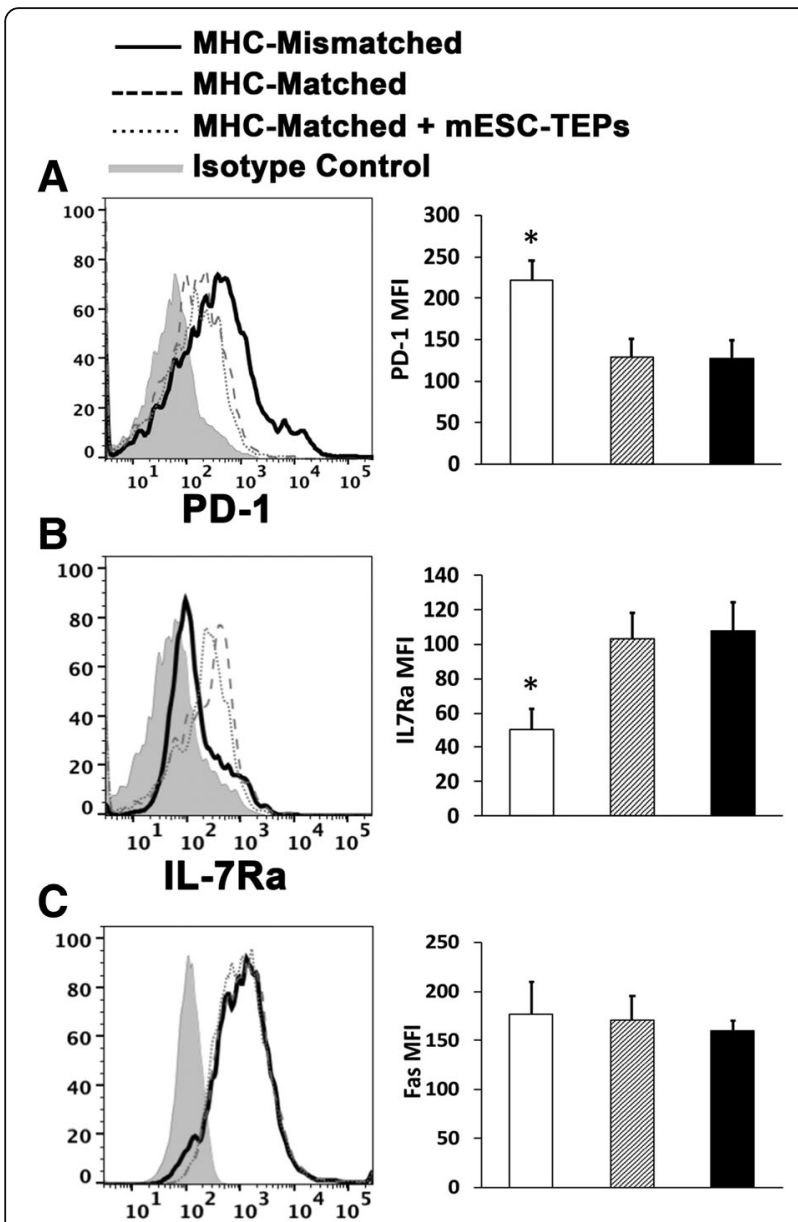

D

FAS
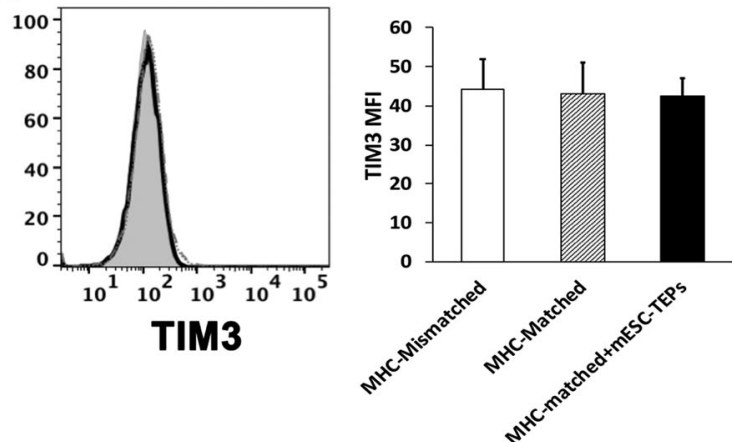

Fig. $5 \mathrm{MHC}$-mismatched mESC-TEP-transplanted mice do not have an upregulated PD-1 and downregulated IL-7Ra expression on host-type peripheral T cells. Wild-type NOD mice were injected i.v. with anti-CD3/ CD8 Abs on days -8 and -3 as in Fig. 1. On day 0 , the conditioned mice were injected i.v. with $\mathrm{BM}$ and $\mathrm{CD}^{+} \mathrm{T}$ cell-depleted spleen cells ( $20 \times 10^{6}$ each) from MHC-matched $\mathrm{H}-2^{9^{7}} \mathrm{~B} 6$ mice or MHC-mismatched B6 mice as in Fig. 1. A group of the MHC-matched BMT recipients was also injected i.t. with B6 mESC-EpCAM1 ${ }^{+}$TEPs $\left(5 \times 10^{4}\right)$ as in Fig. 2. On day 100, the expression of PD-1, IL-7Ra, FAS and TIM3 by residual splenic host-type $T$ cells $\left(C D 45.1^{+} C D 4^{+} T C R \beta^{+}\right)$was analyzed by flow cytometry. The Expression levels of a PD-1, $\mathbf{b} \|-7 R a, \mathbf{c} F A S$ and $\mathbf{d}$ TIM3. One representative FACS profile and mean fluorescence $(n=4-6)$ are shown. ${ }^{*} P<0.05$, vs MHC-matched BM transplants
In addition to the deletion of autoreactive $\mathrm{T}$ cells in the thymus, peripheral tolerance also plays a role in the prevention of insulitis and T1D. Our data suggest that the mechanisms of the peripheral tolerance induced by the two approaches seem also to be different. In the MHCmismatched BMT mice, the residual host-type peripheral $T$ cells were anergic due to upregulation of PD-1 and downregulation of IL-7R $\alpha$. In contrast, transplantation of mESC-TEPs did not lead to the upregulation of PD-1 and downregulation of IL-7R $\alpha$. Instead, it resulted in an enhanced Treg development in the thymus, leading to an increased number of Tregs in the periphery.

Reduced frequency and/or function of Tregs in both NOD mice and T1D patients were observed by some groups [3, 39], although these results were disputed by others $[43,44]$. The importance of Tregs in controlling T1D has been clearly established [3, 45]. For example, NOD mice with Treg defect have an accelerated T1D [46-49]. It has also been shown that the proportion of Tregs in the pancreatic islets progressively decreases with inflammation [50]. We have demonstrated that transplantation of mESC-TEPs leads to an increased number of Tregs that can inhibit the proliferation of Teffs in NOD mice. Our data suggest that the increased number of Tregs plays a role in the prevention of T1D. Although it has been reported that other stem cell technology, such as ESC- or induced pluripotent stem cell (iPSC)-derived pancreatic progenitors and allogeneic hematopoietic stem cell transplant have the potential for curing T1D [51, 52], the mechanisms by which our ESC-TECs ameliorate T1D appear to differ from these approaches.

In this study, we have used mESCs to show the feasibility of ESC-TEPs/TECs to ameliorate insulitis and T1D in NOD mice. Using $\mathrm{mESC}$-derived cells also facilitates mechanistic studies. In the future, we will also test the ability of human ESC- and iPSC-derived TEPs/TECs to prevent and treat T1D. Our present studies using NOD mice have some limitations. For example, we transplanted mESC-TEPs into mice prior to the onset of insulitis. Therefore, this protocol was designed to prevent T1D. In future studies, we will determine the ability of ESC- and iPSC-TEPs/TECs to reverse or treat T1D by transplantation of the cells after the onset of insulitis.

\section{Conclusions}

In summary, we have demonstrated that transplantation of MHC-mismatched mESC-TEPs prevents insulitis and T1D development in NOD mice. This is likely due to the restoration of defects in both central and peripheral tolerance in NOD mice. Our findings justify further evaluation of human ESC- and iPSC-derived TEPs/TECs in the prevention and treatment of T1D in both animals and human patients. 


\section{Additional file}

Additional file 1: Figure S1. Isotype antibody staining for Figs. 1, 2, and 3. (PDF 205 kb)

\begin{abstract}
Abbreviations
Abs: Antibodies; BM: Bone marrow; BMT: BM transplantation; DE: Definitive endoderm; EAE: Experimental autoimmune encephalomyelitis; GVHD: Graftversus-host disease; HLA: Human leukocyte antigen; Ins2: Proinsulin 2; k: Keratin; mESCs: Mouse embryonic stem cells; MHC: Major histocompatibility complex; MOG: Myelin oligodendrocyte glycoprotein; qRT-PCR: Real-time quantitative reverse-transcription and polymerase chain reactions; T1D: Type 1 diabetes; TECs: Thymic epithelial cells; TEPs: Thymic epithelial progenitors; Tregs: Regulatory T cells
\end{abstract}

\section{Acknowledgements}

Not applicable

\section{Authors' contributions}

MS, YL, and LL participated in data collection and analysis. ZH and LL participated in the design of the study. $\mathrm{ZH}$ and $\mathrm{LL}$ participated in the writing of the manuscript and data interpretation. All authors read and approved the final manuscript.

\section{Funding}

This work was supported by grants from NIH (1R01Al123131, LL), Connecticut Regenerative Medicine Research Fund (16-RMB-UCONN-02, LL), National Natural Science Foundation of China (81560211, to MS), Science and Technology Support Program of Guizhou Province[Qiankehezhicheng (2017)2970, to MS], Scientific and Technological foundation for the Excellent Youth Scholars Training by Guizhou Province [Qiankeherenzi (2015)07, to MS], and Guizhou Province's Science and Technology Major Project [Qian-JZhong (2015)2003, to ZH].

\section{Availability of data and materials}

The datasets used and/or analyzed during the current study available from the corresponding author on reasonable request.

\section{Ethics approval and consent to participate}

The protocols for animal studies were approved by the Institutional Animal Care and Use Committee of the University of Connecticut and were conducted in accordance with $\mathrm{NIH}$ guidelines.

\section{Consent for publication}

Not applicable

\section{Competing interests}

The authors declare that they have no competing interests.

\section{Author details}

${ }^{1}$ Department of Human Histology and Embryology, School of Basic Medical Sciences, Stem Cell and Tissue Engineering Research Centre, Guizhou Medical University, Guiyang, Guizhou, China. ${ }^{2}$ Department of Allied Health Sciences, University of Connecticut, 1390 Storrs Road, Storrs, CT 06269, USA. ${ }^{3}$ Key Laboratory for Adult Stem Cell Translational Research, Chinese Academy of Medical Sciences, Guiyang 550004, China. ${ }^{4}$ Department of Pediatrics, Affiliated Hospital of Zunyi Medical College, Zunyi, China. ${ }^{5}$ University of Connecticut Stem Cell Institute, University of Connecticut, Storrs, CT, USA.

Received: 27 December 2018 Revised: 4 July 2019

Accepted: 16 July 2019 Published online: 06 August 2019

\section{References}

1. Chentoufi AA, Binder NR, Berka N, Abunadi T, Polychronakos C. Advances in type I diabetes associated tolerance mechanisms. Scand J Immunol. 2008; 68:1-11.

2. Rossini AA. Autoimmune diabetes and the circle of tolerance. Diabetes. 2004;53:267-75.

3. Spence A, Tang Q. Restoring regulatory T cells in type 1 diabetes. Current Diab Rep. 2016;16:110
4. von Herrath M, Sanda S, Herold K. Type 1 diabetes as a relapsing-remitting disease? Nat Rev Immunol. 2007:7:988-94.

5. Anderson MS, Bluestone JA. The NOD mouse: a model of immune dysregulation. Annu Rev Immunol. 2005;23:447-85.

6. Bakay M, Pandey R, Hakonarson H. Genes involved in type 1 diabetes: an update. Genes. 2013;4:499-521.

7. Kishimoto $\mathrm{H}$, Sprent J. A defect in central tolerance in NOD mice. Nat Immunol. 2001;2:1025-31.

8. Zucchelli S, Holler P, Yamagata T, Roy M, Benoist C, Mathis D. Defective central tolerance induction in NOD mice: genomics and genetics. Immunity. 2005;22:385-96

9. Carrasco-Marin E, Shimizu J, Kanagawa O, Unanue ER. The class II MHC I-Ag7 molecules from non-obese diabetic mice are poor peptide binders. J Immunol. 1996;156:450-8.

10. Stratmann T, Apostolopoulos V, Mallet-Designe V, Corper AL, Scott CA, Wilson IA, et al. The I-Ag7 MHC class II molecule linked to murine diabetes is a promiscuous peptide binder. J Immunol. 2000;165:3214-25.

11. Stadinski BD, Zhang L, Crawford F, Marrack P, Eisenbarth GS, Kappler JW. Diabetogenic T cells recognize insulin bound to IAg7 in an unexpected weakly binding register. Proc Natl Acad Sci U S A. 2010;107:10978-83.

12. Mohan JF, Petzold SJ, Unanue ER. Register shifting of an insulin peptideMHC complex allows diabetogenic T cells to escape thymic deletion. J Exp Med. 2011;208:2375-83.

13. Luhder F, Katz J, Benoist C, Mathis D. Major histocompatibility complex class II molecules can protect from diabetes by positively selecting $T$ cells with additional specificities. J Exp Med. 1998;187:379-87.

14. Slattery RM, Kjer-Nielsen L, Allison J, Charlton B, Mandel TE, Miller JF. Prevention of diabetes in non-obese diabetic I-Ak transgenic mice. Nature. 1990;345:724-6.

15. Beilhack GF, Scheffold YC, Weissman IL, Taylor C, Jerabek L, Burge MJ, et al. Purified allogeneic hematopoietic stem cell transplantation blocks diabetes pathogenesis in NOD mice. Diabetes. 2003:52:59-68.

16. Li H, Kaufman CL, Boggs SS, Johnson PC, Patrene KD, Ildstad ST. Mixed allogeneic chimerism induced by a sublethal approach prevents autoimmune diabetes and reverses insulitis in nonobese diabetic (NOD) mice. J Immunol. 1996:156:380-8.

17. Liang Y, Huang T, Zhang C, Todorov I, Atkinson M, Kandeel F, et al. Donor CD8+ T cells facilitate induction of chimerism and tolerance without GVHD in autoimmune NOD mice conditioned with anti-CD3 mAb. Blood. 2005; 105:2180-8.

18. Nikolic B, Takeuchi Y, Leykin I, Fudaba Y, Smith RN, Sykes M. Mixed hematopoietic chimerism allows cure of autoimmune diabetes through allogeneic tolerance and reversal of autoimmunity. Diabetes. 2004;53:376-83.

19. Racine J, Wang M, Zhang C, Lin CL, Liu H, Todorov I, et al. Induction of mixed chimerism with $\mathrm{MHC}$-mismatched but not matched bone marrow transplants results in thymic deletion of host-type autoreactive T-cells in NOD mice. Diabetes. 2011:60:555-64.

20. Seung E, Iwakoshi N, Woda BA, Markees TG, Mordes JP, Rossini AA, et al. Allogeneic hematopoietic chimerism in mice treated with sublethal myeloablation and anti-CD154 antibody: absence of graft-versus-host disease, induction of skin allograft tolerance, and prevention of recurrent autoimmunity in islet-allografted NOD/Lt mice. Blood. 2000;95:2175-82.

21. Wang M, Racine J, Zhang M, Wu T, Deng R, Johnston $H$, et al. MHCmismatched chimerism is required for induction of transplantation tolerance in autoimmune nonobese diabetic recipients. J Immunol. 2014; 193:2005-15.

22. Tian C, Bagley J, Cretin N, Seth N, Wucherpfennig KW, lacomini J. Prevention of type 1 diabetes by gene therapy. J Clin Invest. 2004;114:969-78.

23. French MB, Allison J, Cram DS, Thomas HE, Dempsey-Collier M, Silva A, et al. Transgenic expression of mouse proinsulin II prevents diabetes in nonobese diabetic mice. Diabetes. 1997;46:34-9.

24. Narendran P, Mannering SI, Harrison LC. Proinsulin-a pathogenic autoantigen in type 1 diabetes. Autoimmun Rev. 2003;2:204-10.

25. Wegmann DR, Eisenbarth GS. It's insulin. J Autoimmun. 2000;15:286-91.

26. Pugliese A, Zeller M, Fernandez A Jr, Zalcberg LJ, Bartlett RJ, Ricordi C, et al. The insulin gene is transcribed in the human thymus and transcription levels correlated with allelic variation at the INS VNTR-IDDM2 susceptibility locus for type 1 diabetes. Nat Genet. 1997:15:293-7.

27. Vafiadis P, Bennett ST, Todd JA, Nadeau J, Grabs R, Goodyer CG, et al. Insulin expression in human thymus is modulated by INS VNTR alleles at the IDDM2 locus. Nat Genet. 1997;15:289-92. 
28. Thebault-Baumont K, Dubois-Laforgue D, Krief $P$, Briand JP, Halbout $P$, Vallon-Geoffroy K, et al. Acceleration of type 1 diabetes mellitus in proinsulin 2-deficient NOD mice. J Clin Invest. 2003;111:851-7.

29. Cetkovic-Cvrlje M, Gerling IC, Muir A, Atkinson MA, Elliott JF, Leiter EH. Retardation or acceleration of diabetes in NOD/Lt mice mediated by intrathymic administration of candidate beta-cell antigens. Diabetes. 1997; 46:1975-82.

30. Marodon G, Fisson S, Levacher B, Fabre M, Salomon BL, Klatzmann D. Induction of antigen-specific tolerance by intrathymic injection of lentiviral vectors. Blood. 2006;108:2972-8.

31. Lynch HE, Goldberg GL, Chidgey A, Van den Brink MR, Boyd R, Sempowski GD. Thymic involution and immune reconstitution. Trends Immunol. 2009; 30:366-73.

32. Lai L, Jin J. Generation of thymic epithelial cell progenitors by mouse embryonic stem cells. Stem Cells. 2009;27:3012-20.

33. Lai L, Cui C, Jin J, Hao Z, Zheng Q, Ying M, et al. Mouse embryonic stem cell-derived thymic epithelial cell progenitors enhance T-cell reconstitution after allogeneic bone marrow transplantation. Blood. 2011;118:3410-8.

34. Su M, Song $Y$, He Z, Hu R, Rood D, Lai L. Administration of embryonic stem cell-derived thymic epithelial progenitors expressing MOG induces antigenspecific tolerance and ameliorates experimental autoimmune encephalomyelitis. J Autoimmun. 2015;58:36-47.

35. Su M, Lin Y, Cui C, Tian X, Lu X, He Z, et al. ESC-derived thymic epithelial cells expressing MOG prevents EAE by central and peripheral tolerance mechanisms. Cell Immunol. 2017;322:84-91.

36. Hu R, Liu Y, Su M, Song Y, Rood D, Lai L. Transplantation of donor-origin mouse embryonic stem cell-derived thymic epithelial progenitors prevents the development of chronic graft-versus-host disease in mice. Stem Cells Trans Med. 2017:6:121-30.

37. Song $Y$, Su M, Zhu J, Di W, Liu Y, Hu R, et al. FOXN1 recombinant protein enhances T-cell regeneration after hematopoietic stem cell transplantation in mice. Eur J Immunol. 2016:46:1518-28.

38. Hu R, Liu Y, Su M, Song Y, Rood D, Lai L. Transplantation of donor-origin mouse embryonic stem cell-derived thymic epithelial progenitors prevents the development of chronic graft-versus-host disease in mice. Stem Cells Transl Med. 2017;6:121-30.

39. Kukreja A, Cost G, Marker J, Zhang C, Sun Z, Lin-Su K, et al. Multiple immuno-regulatory defects in type-1 diabetes. J Clin Invest. 2002;109: 131-40.

40. Chentoufi AA, Polychronakos C. Insulin expression levels in the thymus modulate insulin-specific autoreactive T-cell tolerance: the mechanism by which the IDDM2 locus may predispose to diabetes. Diabetes. 2002;51: 1383-90.

41. Kanagawa O, Martin SM, Vaupel BA, Carrasco-Marin E, Unanue ER. Autoreactivity of T cells from nonobese diabetic mice: an I-Ag7-dependent reaction. Proc Natl Acad Sci U S A. 1998;95:1721-4

42. Faideau B, Lotton C, Lucas B, Tardivel I, Elliott JF, Boitard C, et al. Tolerance to proinsulin-2 is due to radioresistant thymic cells. J Immunol. 2006;177:53-60.

43. Brusko T, Wasserfall C, McGrail K, Schatz R, Viener HL, Schatz D, et al. No alterations in the frequency of FOXP3+ regulatory T-cells in type 1 diabetes. Diabetes. 2007:56:604-12.

44. Mellanby RJ, Thomas D, Phillips JM, Cooke A. Diabetes in non-obese diabetic mice is not associated with quantitative changes in CD4+ CD25+ Foxp3+ regulatory T cells. Immunology. 2007;121:15-28.

45. Visperas A, Vignali DA. Are regulatory T cells defective in type 1 diabetes and can we fix them? J Immunol. 2016;197:3762-70.

46. Salomon B, Lenschow DJ, Rhee L, Ashourian N, Singh B, Sharpe A, et al. B7/ CD28 costimulation is essential for the homeostasis of the CD4+CD25+ immunoregulatory $T$ cells that control autoimmune diabetes. Immunity. 2000;12:431-40

47. Tang Q, Henriksen KJ, Boden EK, Tooley AJ, Ye J, Subudhi SK, et al. Cutting edge: CD28 controls peripheral homeostasis of $\mathrm{CD} 4+\mathrm{CD} 25+$ regulatory $\mathrm{T}$ cells. J Immunol. 2003;171:3348-52.

48. Chen Z, Benoist C, Mathis D. How defects in central tolerance impinge on a deficiency in regulatory T cells. Proc Natl Acad Sci U S A. 2005;102:14735-40.

49. Setoguchi R, Hori S, Takahashi T, Sakaguchi S. Homeostatic maintenance of natural Foxp3(+) CD25(+) CD4(+) regulatory T cells by interleukin (IL)-2 and induction of autoimmune disease by IL-2 neutralization. J Exp Med. 2005;201:723-35.
50. Tang Q, Adams JY, Penaranda C, Melli K, Piaggio E, Sgouroudis E, et al. Central role of defective interleukin-2 production in the triggering of islet autoimmune destruction. Immunity. 2008;28:687-97.

51. Pellegrini S, Piemonti L, Sordi V. Pluripotent stem cell replacement approaches to treat type 1 diabetes. Curr Opin Pharmacol. 2018;43:20-6.

52. McCabe KE, Pollock AJ, Rehm JL, DeSantes KB. Curative potential of allogeneic hematopoietic stem cell transplant in type 1 diabetes. Pediatr Diabetes. 2017;18:832-4.

\section{Publisher's Note}

Springer Nature remains neutral with regard to jurisdictional claims in published maps and institutional affiliations.
Ready to submit your research? Choose BMC and benefit from:

- fast, convenient online submission

- thorough peer review by experienced researchers in your field

- rapid publication on acceptance

- support for research data, including large and complex data types

- gold Open Access which fosters wider collaboration and increased citations

- maximum visibility for your research: over $100 \mathrm{M}$ website views per year

At BMC, research is always in progress.

Learn more biomedcentral.com/submissions 